\title{
Determination of solid/liquid fraction of three aluminium binary alloys using a new single-pan scanning calorimeter
}

\author{
Sinan Savas ${ }^{1,2} \cdot$ Hongbiao Dong ${ }^{1}$
}

Received: 19 July 2016/Accepted: 28 August 2017/Published online: 20 September 2017

(C) Akadémiai Kiadó, Budapest, Hungary 2017

\begin{abstract}
There is an increased demand for data with higher precision for the enthalpy changes and the fraction of solid/liquid temperatures of materials. Therefore, continuous efforts are often devoted to design calorimeters that can accurately measure materials' thermophysical properties. In this study, a new single-pan scanning calorimeter was used to measure the transition temperature and enthalpy change of three aluminium binary alloys. Measured results also were compared with the calculated results using thermodynamic software. The measured high accuracy enthalpy data were used to determine transient temperature. It is concluded that the new instrument is a promising device that can achieve reliable and reproducible materials' thermophysical data.
\end{abstract}

Keywords Calorimeter $\cdot$ SPSC $\cdot$ Enthalpy change $\cdot$ Liquid fraction $\cdot$ Al Alloys

\section{Introduction}

Differential scanning calorimeter (DSC) is a thermal analysis equipment measuring how physical properties of a sample change, along with temperature against time [1]. Calorimetric techniques like DSC and DTA are widely used in research and in industry for the thermal characterization of materials of a wide variety of thermophysical

Sinan Savas

sinansavash@gmail.com

1 Department of Engineering, University of Leicester, University Road, Leicester LE1 7RH, UK

2 Department of Mechanical Engineering, Izmir Institute of Technology, Izmir, Turkey properties [2-5]. These calorimetric methods enable the measurement of various phase transitions as a function of temperature, but they have some limitations and drawbacks including limited accuracy [6]. Commercial DSC instruments require baseline corrections [7]. As an additional drawback of commercial devices, these are not always suitable for use with all purposes because of their fragility, which also limits their use [8]. Although there are reports of some custom-designed thermal analysis devices published on the literature, most of them are not suitable instruments for high-precision measurements [9-13]. If the detection is slow in comparison with the occurring heat effect (thermal lag), smearing of the measurement signal over time occurs [14]. Preferably, the signal should be desmeared to allow for the response of the equipment during rapid changes [15].

The enthalpy changes during melting and freezing were calculated from the measured data using a programme as described in Ref. [16]. The obtained enthalpy data were used to calculate the evolution of mass fraction solid $\left(f_{\mathrm{S}}\right)$ or mass fraction liquid $\left(f_{\mathrm{L}}=1-f_{\mathrm{S}}\right)$. As shown in Eq. (1), if latent heat is assumed to be constant and $C_{\mathrm{P}}$ solid $=C_{\mathrm{P}}$ liquid, the fraction liquid can be determined in Eq. (1).

$f_{\mathrm{L}}=\left[\frac{\left(H-H_{\text {solidus }}\right)-C_{\mathrm{P}}\left(T-T_{\text {solidus }}\right)}{\left(H_{\text {liquidus }}-H_{\text {solidus }}\right)-C_{\mathrm{P}}\left(T_{\text {liquidus }}-T_{\text {solidus }}\right)}\right]$

Equation (1) Equation for liquid fraction calculation [15].

Equation (1) is used to determine the liquid fraction evolution as a function of temperature where $f_{\mathrm{L}}$ is liquid fraction, $H_{\text {solidus }}\left(H_{\mathrm{s}}\right)$ and $H_{\text {liquidus }}\left(H_{1}\right)$ are relevant enthalpies of solid and liquid, $C_{\mathrm{p}}$ is heat capacity, $T_{\text {solidus }}$ and $T_{\text {liqidus }}$ are relevant temperatures of solid and liquid. 


\section{Experimental}

A series of experiments were also carried out with the conventional heat flux DSC, old SPSC and the newly developed SPSC.

The apparent melting or freezing temperature range and enthalpy measurements as a function of temperature of three Al binary alloys are presented. These are including Al-11.68mass\% Si, Al-4.9mass\% Cu and Al-5.58mass\% $\mathrm{Mg}$ and were selected for investigation. A number of measurements were performed by the new calorimeter called single-pan scanning calorimeter (SPSC) to validate the results and its reproducibility.

Figure 1 shows Al-11.68mass\% Si samples that were machined into cylinders [12].

The new SPSC samples were machined into cylinders that were $6 \mathrm{~mm}$ in diameter and $6 \mathrm{~mm}$ in height. For the central thermocouple, a hole of $1 \mathrm{~mm}$ in diameter and about $4 \mathrm{~mm}$ in depth was drilled into the bottom. After machining, the samples were cleaned in an ultrasonic cleaner to remove any dirt from the sample surface. The samples were then rinsed with water and dried.

Figure 2 shows $\mathrm{Al}-4.9$ mass\% $\mathrm{Cu}$ samples that were machined into cylinders. After machining, the samples were cleaned in the same procedure like the previous samples.

Figure 3 shows samples that were machined into cylinders. After machining, the samples were cleaned in the same procedure like the previous samples.

A chemical composition of three binary $\mathrm{Al}$ alloys is shown in Table 1 [12]. The supplier company is Beijing General Research Institute for Non-ferrous Metals (GRINM).

Three different sizes, small, medium and large samples, were therefore presented for the DSC, the new SPSC and the old SPSC, respectively.

Those alloy samples were weighed, and their mass is given in Table 2.

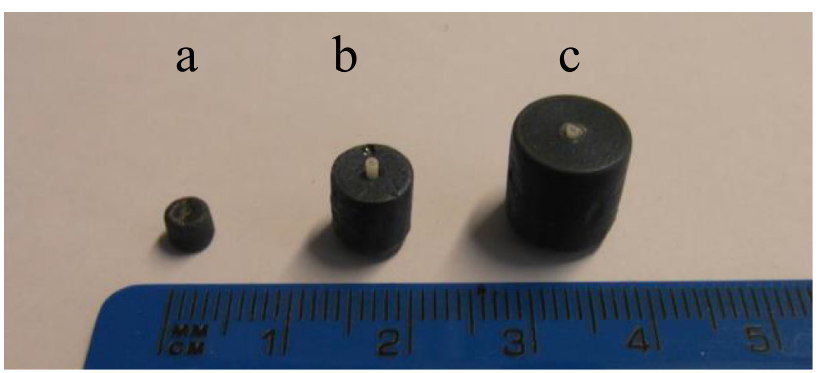

Fig. 1 Al-11.68mass \% Si samples for $a$ DSC, $b$ new SPSC and $c$ old SPSC

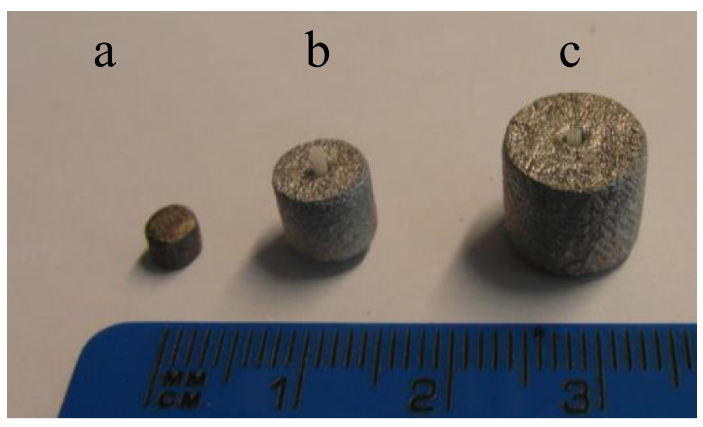

Fig. $2 \mathrm{Al}-4.9$ mass\% $\mathrm{Cu}$ samples for $a \mathrm{DSC}, b$ new SPSC and $c$ old SPSC

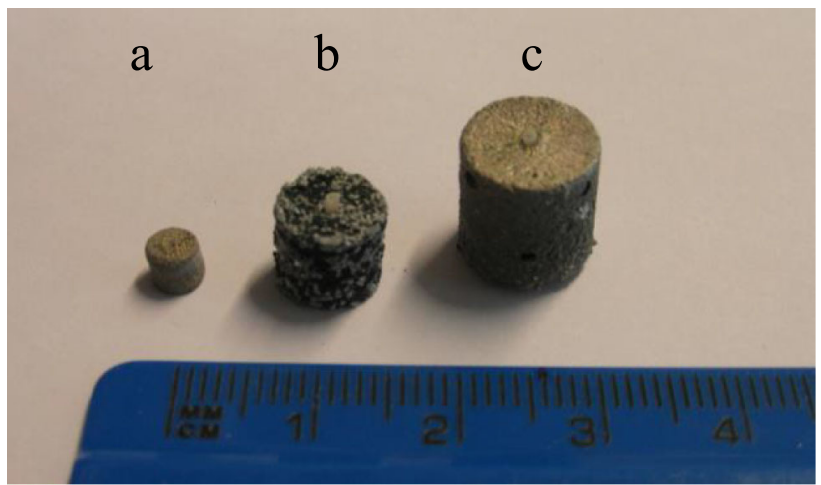

Fig. $3 \mathrm{Al}-5.58 \mathrm{mass} \% \mathrm{Mg}$ samples for $a \mathrm{DSC}, b$ new SPSC and $c$ old SPSC

\section{DSC measurements}

NETZSCH DSC 404 C/6/G Pegasus was used in this study. This instrument has a platinum wire furnace and R-type thermocouples. The temperature range is from -120 to $1650{ }^{\circ} \mathrm{C}$, and heating and cooling rates are from 0.1 to $50 \mathrm{~K} \mathrm{~min}^{-1}$.

Experiments were conducted in an argon-controlled environment. Argon purge gas with a purity of $99.996 \%$ was used in all cases.

The high-purity $\mathrm{Al}_{2} \mathrm{O}_{3}$ pan was used as reference material. The standard heating rates in the DSC are 3 and $10 \mathrm{~K} \mathrm{~min}^{-1}$. The samples were heated to $700{ }^{\circ} \mathrm{C}$ at $3 \mathrm{~K} \mathrm{~min}^{-1}$ (or $10 \mathrm{~K} \mathrm{~min}^{-1}$ ) and then cooled to $30^{\circ} \mathrm{C}$ at the same rate. All samples were put in an $\mathrm{Al}_{2} \mathrm{O}_{3}$ pan with an $\mathrm{Al}_{2} \mathrm{O}_{3}$ lid. Argon was fed through the system at a flow rate of $35 \mathrm{~mL} \mathrm{~min}{ }^{-1}$ to minimize oxidation of the samples. Three repetitions were carried out for each sample under the same condition.

There are two main types of DSC: the heat flux DSC and the power-compensating DSC. Both types have two pans and operated by scanning the temperature. The differential scanning calorimeter (DSC) is shown schematically in Fig. 4. 
Table 1 Composition of three binary Al alloys

\begin{tabular}{lllllll}
\hline Binary alloy & \multicolumn{2}{l}{ Chemical composition/mass\% } & & & \\
\cline { 2 - 7 } & $\mathrm{Si}$ & $\mathrm{Cu}$ & $\mathrm{Mg}$ & $\mathrm{Fe}$ & $\mathrm{Ca}$ & $\mathrm{Ni}$ \\
\hline $\mathrm{Al}-12 \mathrm{Si}$ & 11.68 & - & - & 0.042 & $<0.02$ & - \\
$\mathrm{Al}-5 \mathrm{Cu}$ & - & 4.9 & & - & - & 0.0002 \\
$\mathrm{Al}-5 \mathrm{Mg}$ & 0.0028 & 0.0006 & 5.58 & 0.0044 & - & $<0.0004$ \\
\hline
\end{tabular}

Table 2 Mass of analysed samples

\begin{tabular}{llll}
\hline Sample & Device & & \\
\cline { 2 - 4 } & DSC & Old SPSC & New SPSC \\
& Mass/mg & & \\
\hline $\mathrm{Al}-\mathrm{Si}$ & 22 & 700 & 2050 \\
$\mathrm{Al}-\mathrm{Cu}$ & 22 & 700 & 2050 \\
$\mathrm{Al}-\mathrm{Mg}$ & 22 & 700 & 2050 \\
\hline
\end{tabular}

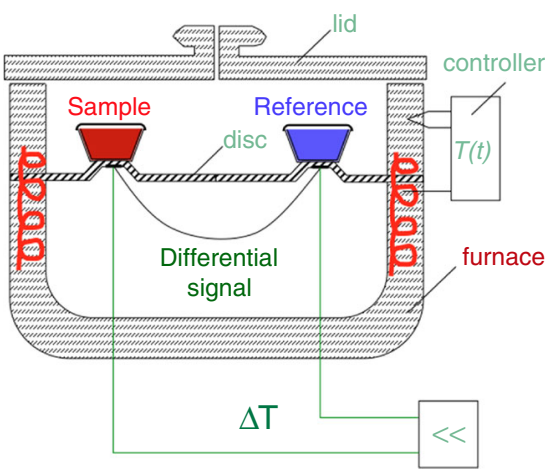

Fig. 4 A schematic diagram of two-pan DSC [10]

\section{SPSC measurements}

The basis of SPSC is to monitor the sample temperature as a function of time and to measure or control the heat flux across the wall of part of the calorimeter.

The single-pan scanning calorimeter is calibrated by running experiments with a standard specimen of known specific heat and empty pan.

Three runs are routinely carried out for calibration, the empty pan, the sample in the empty pan and the calibrant in the empty pan. In this work, pure sapphire was used for calibration of latent heat and pure $\mathrm{Al}$ was used for the calibration of temperature. Aluminium rod with a high purity of 99.999\% (AL007901) was supplied by Goodfellow Company.

Figure 5 shows the sectional view of SPSC furnace.

Figure 6 shows the sectional view of new SPSC pans, and Fig. 7 shows the top view of new SPSC pans.

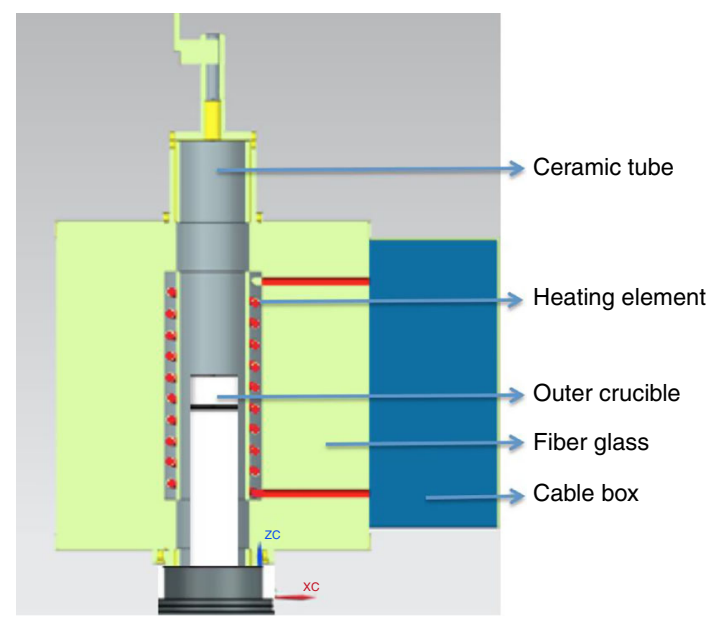

Fig. 5 A Section view of SPSC furnace

All the samples were machined into cylinders $10 \mathrm{~mm}$ in diameter and height for old SPSC. A hole of $1.0 \mathrm{~mm}$ in diameter and about $6 \mathrm{~mm}$ in depth was drilled into the bottom for the central thermocouple. As shown in Fig. 8 [9], there is only one thermocouple for sample (S), one thermocouple for inner crucible (A), and one thermocouple for outer crucible (B) and finally one thermocouple is for the furnace.

The measurements with the new SPSC were carried out using a constant heat flux mode. By monitoring the heat flux at a constant rate of temperature change, thermal events can be monitored. Argon was fed through the system at a flow rate of $35 \mathrm{~mL} \mathrm{~min}^{-1}$ to minimize oxidation of the samples.

The temperature difference between the inner and outer crucibles is kept constant in the constant heat flux mode. In this experiment, a value of $6 \mathrm{~K}$ was used for heating and $-6 \mathrm{~K}$ for cooling. The inner crucible was alumina and the outer crucible boron nitride; this gives a heating or cooling rate in the absence of latent heat evolution of about $4 \mathrm{~K} \mathrm{~min}^{-1}$.

\section{Results for Al-11.68mass\% Si alloy}

Figure 9 shows the temperature of melting and cooling curve on a more detailed scale. The temperature variation during melting and solidification is very small. 
Fig. 6 A schematic diagram of new SPSC pans (sectional view) (12)

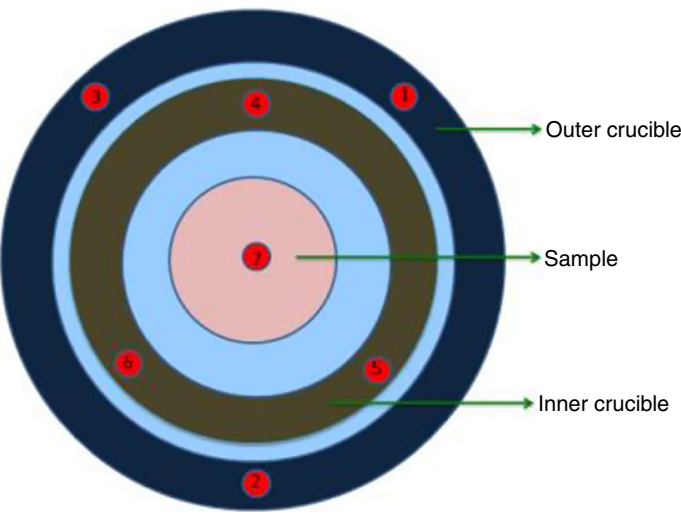

Fig. 7 A schematic diagram of new SPSC pan (top view)

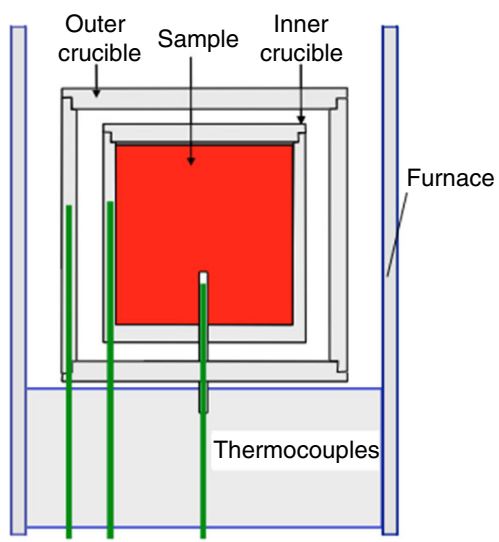

Fig. 8 A schematic diagram of old SPSC pan (9)

Figure 10 shows measured enthalpy change of Al11.68 mass \% Si alloy for new SPSC. Figure 10 shows that there is an initial transient, a plateau for about $50 \%$ of the width, then a gradual rise in temperature and a short final transient [16].

Figure 11 shows a comparison of liquid fraction as a function of temperature of $\mathrm{Al}-11.68$ mass $\% \mathrm{Si}$ alloy for SPSC and DSC, together with prediction curve of the Scheil mode.

The relationships of liquid fraction-temperature were calculated through DSC and SPSC and are compared

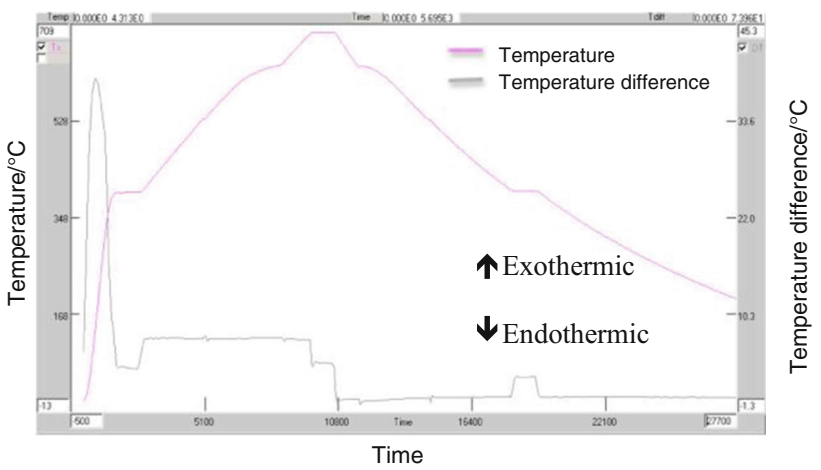

Fig. 9 A plot of temperature and temperature difference of $690 \mathrm{mg}$ Al-11.68mass\% Si alloy for new SPSC for $3.1 \mathrm{~K} \mathrm{~min}^{-1}$ cooling and heating rate

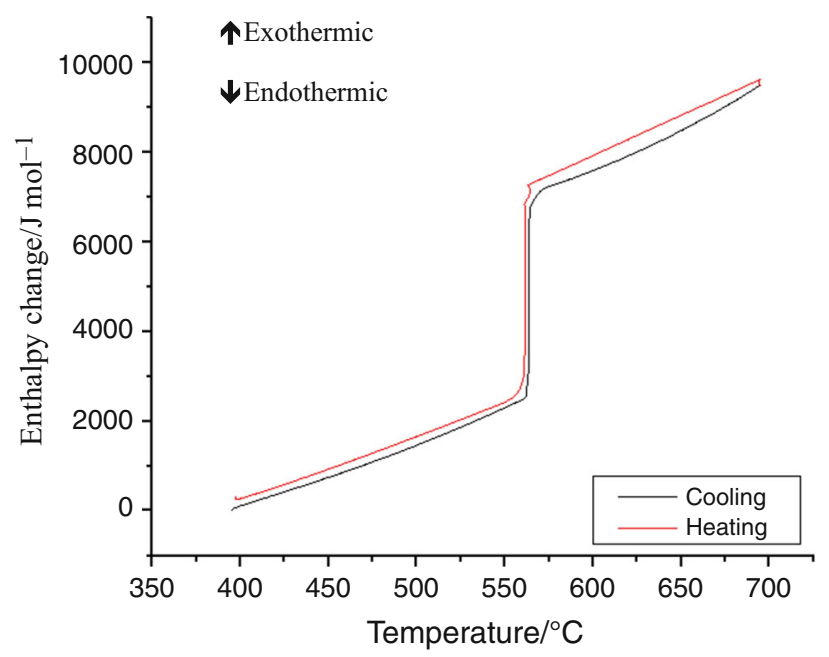

Fig. 10 Measured enthalpy of $690 \mathrm{mg}$ Al-11.68mass\% Si alloy for new SPSC for $3.1 \mathrm{~K} \mathrm{~min}^{-1}$ cooling and heating rate

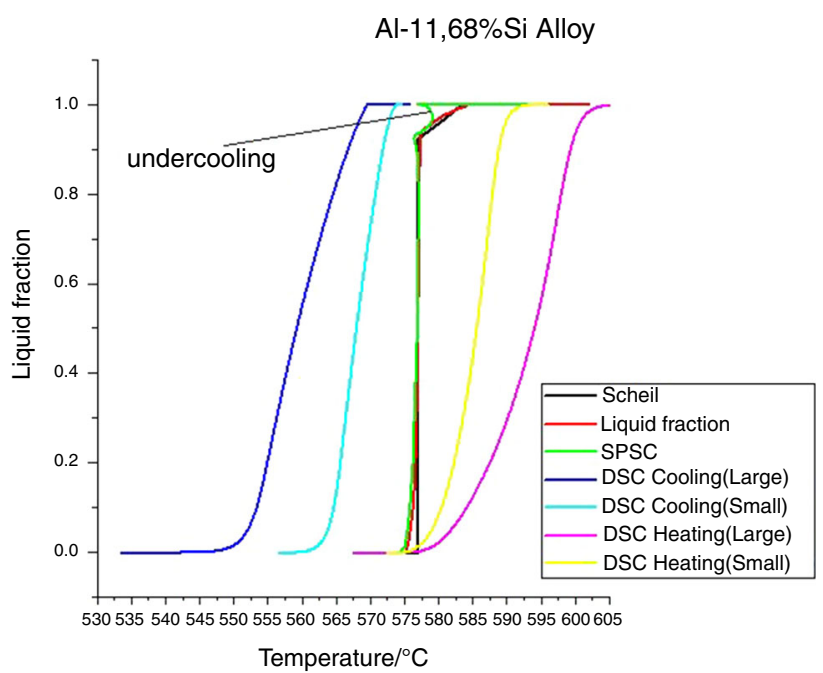

Fig. 11 Comparison of liquid fraction as a function of temperature of $690 \mathrm{mg} \mathrm{Al}-11.68 \mathrm{mass} \% \mathrm{Si}$ alloy for DSC and new SPSC for $3.1 \mathrm{~K} \mathrm{~min}^{-1}$ cooling and heating rate, together with prediction curve 
[17-20]. It can be seen that all heating curves from DSC are lying on the right-hand side of the Scheil curve, while all the cooling curves of DSC are lying on the left-hand side of the Scheil curve since heating is endothermic process and cooling is exothermic process. The SPSC curves are the closest ones to simulation results.

The liquid fraction was estimated from the area per cent of the DSC heating and cooling curves, respectively. All the curves are lying as they are shown on the labels.

In the SPSC cooling curves, the undercooling occurs at the beginning of freezing. The solidus temperatures for alloys on the DSC heating curves are the same. In addition, the obtained knee on the heating curve contains more liquid than the SPSC, Scheil and DSC cooling curves.

\section{Results for Al-4.9mass\% Cu alloy}

Figure 12 shows the temperature of melting and cooling curve on a more detailed scale. The temperature variation during melting and solidification is very small.

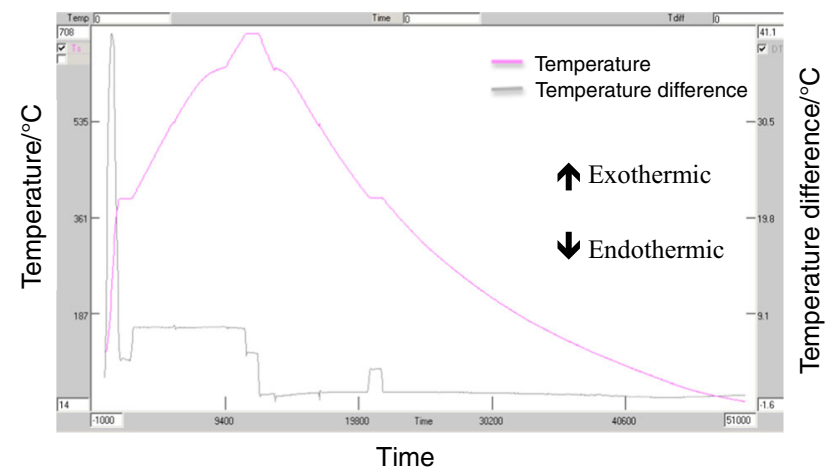

Fig. 12 A plot of temperature and temperature difference versus time of $700 \mathrm{mg} \mathrm{Al}-4.9 \mathrm{mass} \% \mathrm{Cu}$ for new SPSC for $3.1 \mathrm{~K} \mathrm{~min}^{-1}$ cooling and heating rate

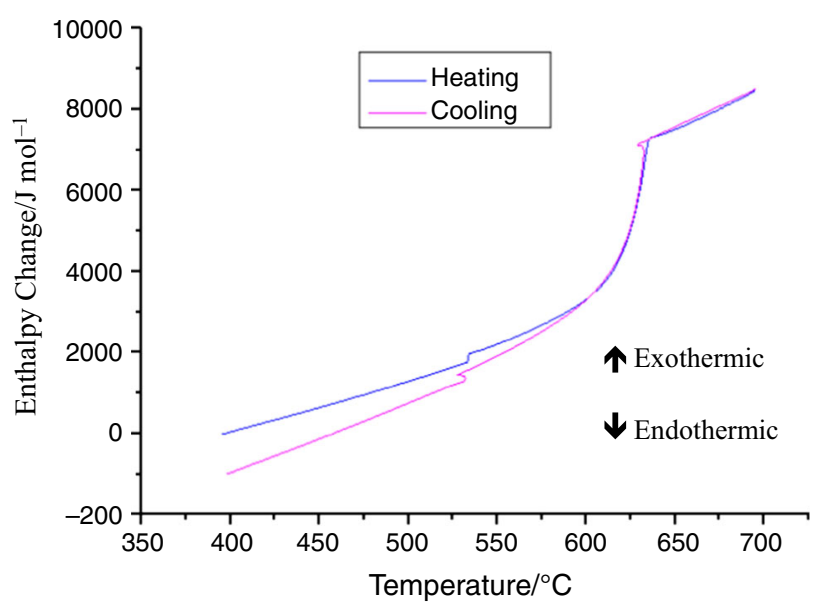

Fig. 13 Measured enthalpy of $700 \mathrm{mg}$ Al-4.9mass\% $\mathrm{Cu}$ alloy for new SPSC for $3.1 \mathrm{~K} \mathrm{~min}^{-1}$ cooling and heating rate
Figure 13 shows measured enthalpy change from new SPSC for Al-4.9mass\% Cu alloy. Figure 14 shows the liquid fraction/temperature relationships calculated by the DSC and SPSC data for $\mathrm{Al}-4.9 \mathrm{mass} \% \mathrm{Cu}$ with the prediction curve. The same conclusions regarding the curves positions can be made for Al-Si alloys. As for Al- 0.98 mass \% Cu alloy, the solidus temperatures of DSC heating is much higher than the prediction data, which is $547{ }^{\circ} \mathrm{C}$.

\section{Results for Al-5.58mass\% Mg alloy}

Figure 15 shows a plot of temperature and temperature difference versus time, and Fig. 16 shows measured enthalpy change from new SPSC for Al-5.58mass\% Mg alloy.

Figure 17 shows the liquid fraction/temperature relationships of Al-5.58mass\% Mg for the DSC and new SPSC data with the prediction curve.

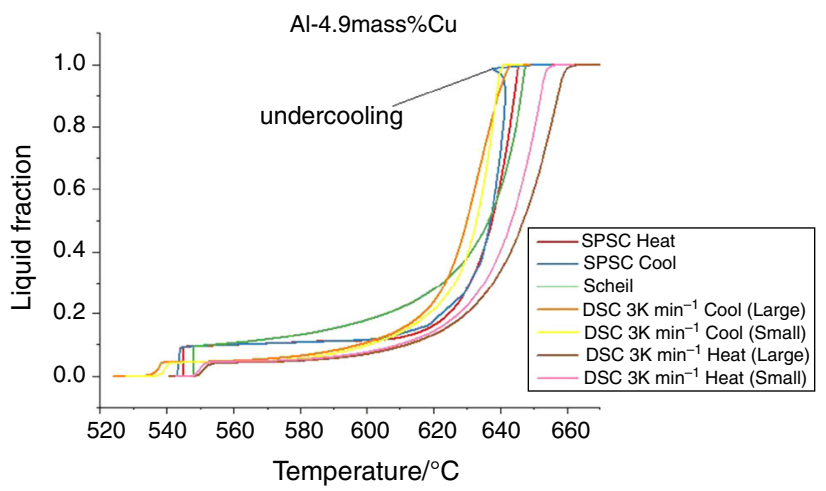

Fig. 14 Comparison of liquid fraction as a function of temperature of $700 \mathrm{mg} \mathrm{Al}-4.9 \mathrm{mass} \% \mathrm{Cu}$ for DSC and SPSC for $3.1 \mathrm{~K} \mathrm{~min}^{-1}$ cooling and heating rate together with prediction curve of Scheil model

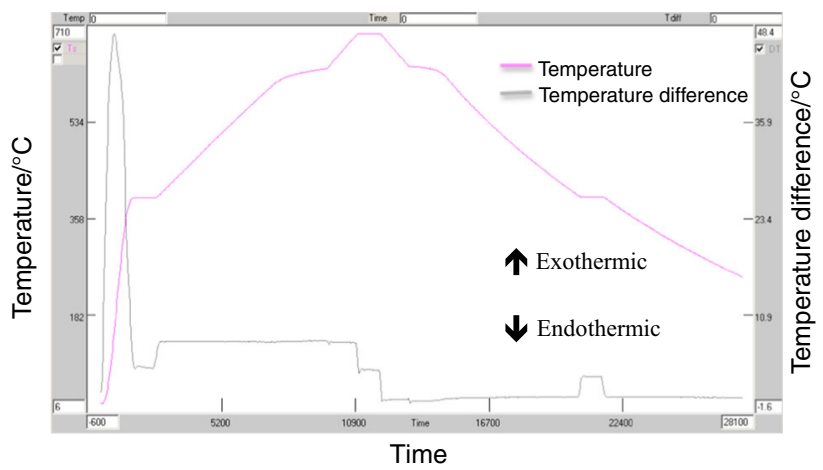

Fig. 15 A plot of temperature and temperature difference versus time of $710 \mathrm{mg}$ Al-5.58mass\% Mg for new SPSC for $3.1 \mathrm{~K} \mathrm{~min}^{-1}$ cooling and heating rate 


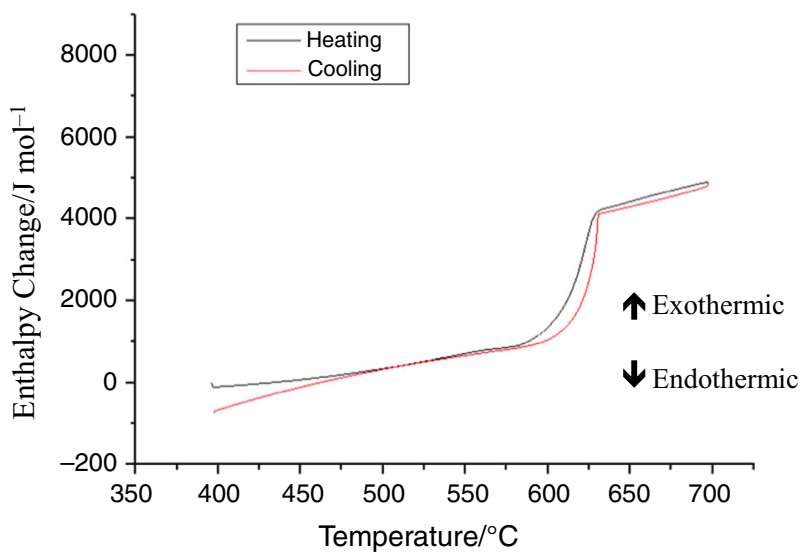

Fig. 16 Measured enthalpy of $710 \mathrm{mg} \mathrm{Al}-5.58 \mathrm{mass} \% \mathrm{Mg}$ alloy for new SPSC for $3.1 \mathrm{~K} \mathrm{~min}^{-1}$ cooling and heating rate

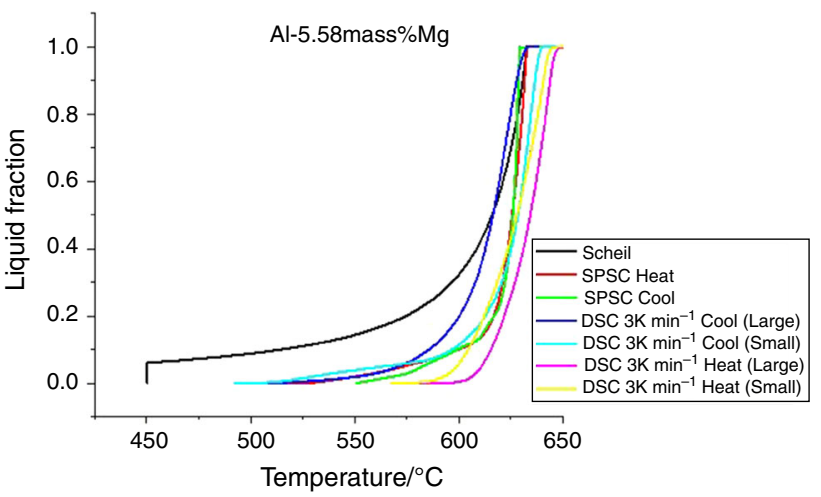

Fig. 17 Comparison of liquid fraction as a function of temperature of $710 \mathrm{mg} \mathrm{Al}-5.58$ mass $\% \mathrm{Mg}$ for DSC and SPSC for $3.1 \mathrm{~K} \mathrm{~min}^{-1}$ cooling and heating rate, together with prediction curve of Scheil model

\section{Discussion}

An important consideration in the modelling of solidification of alloys is the generation of thermal profiles in the solidifying casting [21]. Information about the non-equilibrium process is needed for a number of reasons. It may be necessary to modify microstructure to obtain particular properties, to input enthalpy evolution as a function of temperature in a casting model, to provide liquid fraction as a function of temperature or to control the freezing range [22].

Computational thermodynamics simulation is one of the methods to predict the relationship of fraction liquidtemperature [7]. For example, results on the calculation of solidification using the Scheil simulation have proved to be successful in a number of cases [23]. For Al alloys, it appears particularly successful, allowing not only very accurate predictions for fraction solid transformed as a function of temperature, but also for predicting the phase which appears during solidification [24, 25].
Although it is not always easy to measure liquid fraction as a function of temperature thermal analysis, techniques are also used to give an estimate of the liquid fraction as a function of temperature [26]. Problems arise in practice since it may not be possible to extrapolate the enthalpy of solid from a low temperature because heat has other effects including latent heat effect. Other problems also arise in conventional two-pan DSC if the raw data are not corrected for temperature smearing.

The DSC is controlled to the ramp rate, while the SPSC is using a constant heat flux mode [27]. The DSC curves change significantly due to the influence of the sample mass and the heating rate, which affects the liquid fraction versus temperature. For SPSC, when melting or solidification occurs, the measured temperature is exactly the sample's temperature. For the DSC with two pans, to minimize errors, it is generally recognized that small samples and low heating/cooling rates must be used when latent heat is evolved. Even when samples are small, the errors have been reduced, but not eliminated.

With the $10 \mathrm{~K} \mathrm{~min}^{-1}$ DSC heating rate, a higher temperature is required than for the $3 \mathrm{~K} \mathrm{~min}^{-1}$ heating rate to form the same fraction of liquid. Moreover, the knee on the liquid fraction-temperature curve occurs at a higher temperature. One of the reasons is that with a higher heating, the solute cannot be redistributed rapidly over a short time interval to obtain areas with a composition suitable for melting.

Single-pan scanning calorimetry (SPSC) can also be used to give an estimate of the liquid fraction as a function of temperature. In the simplest approach, the enthalpy versus temperature plot is extrapolated below the liquidus temperature and the enthalpy when completely solid is extrapolated to higher temperatures where melting has stated. During cooling, the fractional distance between the lines gives a measure of the latent heat still to be evolved. Knowing the enthalpy change for each of the phases allows the fraction remaining liquid to be estimated.

The enthalpy change, liquid fraction and enthalpy change for Al-11.68mass\% Si, Al-4.9mass\% Cu, and Al$5.58 \mathrm{mass} \% \mathrm{Mg}$ are plotted as a function of temperature. The experiments were carried out using a constant heat flux mode. On cooling, solid Al forms first; then, eutectic is formed at about $650{ }^{\circ} \mathrm{C}$. The melting and freezing enthalpy lines are similar, except for supercooling before aluminium and the other eutectic phase nucleates. The fraction solid plot shows aluminium being deposited on cooling, and then, a sudden transformation to solid as the eutectic is deposited.

Pure Al should melt and freeze at one temperature. In the present work, the variation was about an order of magnitude less than those found for 20-mg samples using a conventional two-pan DSC. Despite the fact that the 
variation in the present work is small, a variation was observed and its cause should be understood. The variation could be the result of several effects. The temperature might vary because of the:

1. Kinetics of the melting or freezing process.

2. Contamination of the metal with the inner crucible material.

3. Heat flow through the sample thermocouple.

4. Other facts such as nucleation of a new phase mainly at cooling process can substantially influence the temperatures.

\section{Conclusions}

Three Al binary alloys haves been investigated. The studies reveal that the calculated results predicted by Thermo-Calc (Version: TCW5) show the same pattern with experimental results in the relationship of fraction liquid-temperature.

The SPSC results are closer to the prediction results than DSC curves even with the relatively large sample size associated with new SPSC. This is potentially a significant result as conventionally one of the difficulties is predicting the liquid fraction versus temperature. This improvement was obtained by fixing the sample position and crucibles together with the thermocouples while the furnace was positioned by linear automation. Further improvements were obtained through a new arrangement of imbricated crucibles together with three thermocouples inserted in each crucible.

For the constant heat flux run, after the initial transient the temperature remains very constant until about $50 \%$ of the solid is melted. It then begins to rise slowly. A possible reason for this rise is that the solid has melted around the thermocouple and temperature difference builds up in the liquid between the thermocouple tip and the melting interface.

A summary of the experimental results is given below.

A number of alloys including Al-11.68mass\% Si, Al4.9mass\% $\mathrm{Cu}$ and $\mathrm{Al}-5.58 \mathrm{mass} \% \mathrm{Mg}$ have been also simulated by the thermodynamic prediction software ThermoCalc and have been analysed with a conventional DSC and with old and new SPSC.

The SPSC results of the relationship of fraction liquidtemperature are more close to prediction results than DSC curves. It is concluded that the new SPSC provides a powerful technique to understand the transformations that occur in simple and complex alloys even with relatively larger samples used.

Acknowledgements The experimental part of this work was carried out in the University of Leicester. I acknowledge the collaboration for Duyao Zhang to help me to do the theoretical predictions on a programme called Thermo-Calc and for supplying me samples and experimental data for DSC measurement to allow me to compare the results with my experimental data.

\section{References}

1. Hohne G, Hemminger W, Flammersheim HJ. Differential scanning calorimetry: an introduction for practitioners. Berlin: Springer; 1996.

2. Gill P, Moghadam TT, Ranjbar B. Differential scanning calorimetry techniques: applications in biology and nanoscience. J Biomol Tech. 2010;21(4):167-93.

3. Mathot VBF. Thermal analysis and calorimetry beyond 2000: challenges and new routes. Thermochim Acta. 2000;355:1-33.

4. Zhai W, Wang WL, Geng DL, Wei B. A DSC analysis of thermodynamic properties and solidification characteristics for binary Cu-Sn alloys. Acta Mater. 2012;60(19):6518-27.

5. Boettinger WJ, Kattner R. On differential thermal analyzer curves for the melting and freezing of alloys. Metall Mater Trans A. 2002;33(6):1779-94.

6. Dong HB, Hunt JD. A comparison of a novel single-pan calorimeter with a conventional heat-flux differential scanning calorimeter. High Temp High Press. 2000;32(3):311-9.

7. Djurdjevic MB, Francis R, Sokolowski JH, Emadi D, Sahoo M. Comparison of different analytical methods for the calculation of latent heat of solidification of $3 \mathrm{XX}$ aluminum alloys. Mater Sci Eng A. 2004;386(1-2):277-83.

8. Martínez LM, Videa M, Mesquita J. Design, construction and calibration of a portable multi sample DTA setup. Amsterdam: Elsevier; 2013.

9. Dong HB, Hunt JD. A novel single-pan scanning calorimeter measurement of thermophysical properties of metallic alloys. J Therm Anal Calorim. 2001;64:341-50.

10. Dong HB, Hunt JD. A numerical model of a two-pan heat-flux DSC. J Therm Anal Calorim. 2001;64:167-76.

11. Dong HB, Hunt JD. A numerical model for heat flux DSCs: determining heat transfer coefficients within a DSC. Mater Sci Eng. 2005;413-414:470-3.

12. Savas S. A systems approach in product design of a novel singlepan scanning calorimeter. Ph.D. Thesis Department of Engineering. 2014.

13. Kohler F, Campanella T, Nakanishi S, Rappaz M. Application of single pan thermal analysis to $\mathrm{Cu}-\mathrm{Sn}$ peritectic alloys. Acta Mater. 2008;56:1519-28.

14. Kempen ATW. Calibration and smearing of a differential thermal analysis measurement signal upon heating and cooling. Thermochim Acta. 2001;383:21-30.

15. Quested P, Brooks R. Measurement of thermophysical properties at high temperatures for liquid, semisolid, and solid commercial alloys. In: ASM handbook, metals process simulation, vol 22B. 2010. pp. 33-45.

16. Dong HB, Shin MRM, Kurum EC, Cama H, Hunt JD. Determination of liquid fraction during solidification of aluminium alloys using a single-pan scanning calorimeter. Fluid Phase Equilib. 2003;212(1-2):199-208.

17. Dong HB, Shin MRM, Kurum EC, Hunt JD, Cama H. A study of microsegregation in $\mathrm{Al}-\mathrm{Cu}$ using a novel single-pan scanning calorimeter. Metall Mater Trans A. 2003;34:441-7.

18. D'Souza N, Dong HB. Determination of transition temperatures during freezing and melting of interdendritic phases in Ni based superalloys. Mater Sci Technol. 2011;27(1):325-31.

19. D’Souza N, Feitosa LM, West GD, Jones NG, Dong HB. Effects of solute trapping on solidification path in Ta-rich Ta-Al-Fe ternary alloys under rapid freezing. J Alloy Compd. 2017;698:433-41. 
20. Dong HB, Brooks R. Determination of liquidus temperature in $\mathrm{Al}-\mathrm{Si}$ and $\mathrm{Al}-\mathrm{Si}-\mathrm{Mg}$ alloys using a single-pan scanning calorimeter. Mater Sci Eng A. 2005;413-414:480-4.

21. Sharma DGR, Krishnan M, Ravindran C. Determination of the rate of latent heat liberation in binary alloys. Mater Charact. 2000;44(3):309-20.

22. Quested P, Brooks R, Monaghan B. The prediction of thermophysical properties for modelling solidification of metallic melts. High Temp Mater Process. 2011;22(5-6):247-56.

23. Lu H, Zhang F. Microstructural evolution and thixoformability of semi-solid aluminum 319s alloy during re-melting. J Alloy Compd. 2015;649:204-10.
24. Fredriksson H, Rogberg B. Thermal analysis for interpretation of solidification cycle. Metal Sci. 1979;13(12):685-90.

25. Gibbs JW, Kaufman MJ, Hackenberg RE, Mendez PF. Cooling curve analysis to determine phase fractions in solid-state precipitation reactions. Metall Mater Trans A Phys Metall Mater Sci. 2010;41(9):2216-23.

26. Salamon B, Gaune-escard M. Instrumentation and calibration of the Calvet calorimeter Enthalpy of solution of $\mathrm{PrBr}_{3}$ at standard conditions. J Therm Anal Calorim. 2012;108(2):421-4.

27. Iiyoshi R, Niwa $H$, Takematsu $H$. The Utility of phase correction in modulated DSC. J Therm Anal. 2014;1:1039-44. 